\title{
Litchi (Litchi chinensis Sonn.) Products and Processing Technologies: an Update
}

\section{Tanmay Sarkar, Pritha Nayak, Runu Chakraborty*}

Department of Food Technology and Biochemical Engineering, Jadavpur University, Kolkata, India.

Key words: Litchi production, Litchi cultivars, Shelf Life Extension,

\section{Abstract}

Litchi (Litchi chinensis Sonn.) is one of the most relished fruits in India. In the present review, historical background of litchi has been discussed. Litchi production scenario all over India has been outlined. Several Litchi varieties like Shahi, China, Early Bedana, Late Bedana, Bombai to name a few have been enlisted as well as some litchi based products like dried litchi, canned litchi, frozen litchi, litchi honey, litchi wine, health beneficial litchi drinks to name a few have been documented. The processing techniques like some advanced procedure of drying, canning, pollination, fermentation, high-pressure processing of fruits for the said products have also been discussed. We have paid attention to some of the products that have been commercialized and need to be commercialized in this review.

(RDI) of 6 minerals (P, K, Mg, Fe, Zn, Mn) and $22 \%$ for copper (Wall, 2006).Due to its various nutritional and sensory qualities, litchi fruit can be an important contrivance in the food industry (Beristain etal., 2006).

It is seen that area of litchi cultivation has increased from 72 ,00o hectares in 2008-09 to 78,00o hectares in 2010-11 and production of litchi increased from 423 to 497 thousand tons in India. Export of litchi has also increased from 161.5 tons in 2007-08 to 319.93 tons in 2011-12 (APEDA database) (Kumar, 2011).In India, Litchi is grown mostly in the states of Bihar, West Bengal, Assam, Jharkhand and Punjab (Fig-1). Out of the total production in India, 45.6\% is contributed by Bihar and West Bengal is in the second place (17.1\%) (Kumar, 2011).

In order to keep the fruit available round the year in the market several litchi based products are developed (Reyes et al.., 2016). Litchis are generally eaten fresh, but can also be consumed as other products like dried litchi, litchi juice, canned litchi, frozen litchi, litchi honey, litchi wine, litchi squash to name a few (Singh et al., 2012; Shivakumar \& Korsten, 2011; Vural \& Karaman, 2009; Vijayanand et al., 2010; Zhao et al., 2014). Several technologies like high-pressure processing (Chaikham et al., 2017; Hulle et al., 2017; Kaushik et al., 2016; Jayachandran et al., 2015), pasteurization (Chaikham et al., 2017) have been adopted to process whole litchi fruit, pulp and juice to enhance the shelf life of litchi based products (Chaikham et al., 2017; Prakash et al., 2017).

In spite of being highly sensorial and nutritionally recommended, a very few scientific reports have been 
published on litchi based products. The aim of the present review is to document the popular varieties available in India, also the litchi based products that are consumed worldwide along with the technology employed for manufacturing them. This paper also tries to find out the historical connection of Litchi production in the Indian subcontinent (Karizaki, 2017).

\section{Historical background:}

The exact origin of litchi is South China, but the name of the specific area is still unknown. In ancient Chinese history, the emperor Wu Ti transplanted hundreds of litchi trees at his capital Chang An (now Sian) in Shensi province and he also built a palace called Exalted lychee palace. When the capital shifted from Chang An to Ling An in Cheaking province, Chen Purple and Sung Fragrant litchis of Hingwa started to be recorded as outstanding. Therefore, the culture got established for the first time between Indo-China \& China border (Chen, Culture of lychee).

Litchi was introduced in India through Burma and now India contributes to $20 \%$ of world's quality litchi production. Litchi cultivation is now one of the most important growth contributors towards the economy of the state of Bihar in India (Singh \& Babita, 2002).

\section{Litchivarieties:}

There are several varieties of litchi grown in India under different climate and soil conditions. Genetic factors also influence the fruit shape, size, and taste. Indian cultivars greatly vary in 3 different characteristics namely flushing pattern, flush colour and flowering ability. Cultivars were classif ied in 5 categories based on these characteristics, (i) Group A, the early group, (ii) Group B and C are midseason, (iii) Group D being the late group and (iv) Group E, whose cultivation is conf ined to Muzaffarpur is the latest to occur.

a) Shahi: one of the most popular cultivars grown in North Bihar, Jharkhand, Uttaranchal and Uttar Pradesh region in India. This cultivar is earliest to arrive, from the second week of May to the first week of June at various locations in India. Trees of this cultivar produce fruits ranging from $100-150 \mathrm{~kg} /$ tree and the fruits are light in weight(20-25g each). The more the fruit matures the more it is prone to cracking in zones in low humidity and poor moisture content in soil. The pulp of the fruit is greyish white, soft, juicy and sweet with TSS content ranging from $19-22^{\circ} \mathrm{B}$. Seed size varies proportionally with the fruit size (Singh \& Babita, 2002).

b) China: the name 'China' was selected for this cultivar because of its superiority. This medium late season cultivar is tolerant to heat waves and fluctuations in soil moisture. Fruits ripen from May end to June end in different states of India. Trees of China cultivar are smaller than that of the other cultivars and they are high yielding. Fruits are tyrant rose coloured, medium heavy. The fruit pulp is white, soft, juicy, sweet having TSS of $17-180 \mathrm{oB}, 11 \%$ total sugar and $0.43 \%$ acidity. The seeds are dark chocolate in colour, oblong to concave shaped and medium in size. Weight ratio of rind, pulp and seed is 16.42:69.22:14.36. (Singh \& Babita, 2002).

c) Early Bedana: this cultivar ripens early and usually have small seeds. This may be a reason for calling this variety 'Early Seedless' in Punjab. It is a medium fruit yielding cultivar and fruits are generally of $15-18 \mathrm{~g}$ weight having oval or heart shape, rough surface with uranium green skin (Singh \& Babita, 2002). The skin is covered with red tubercles at maturity (Kumar, 2011). The pulp of the fruit is white, soft and juicy while the seed is very small, shrunken, shiny and dirty chocolate in colour. The TSS of the pulp ranges between 17.2-19.8 ${ }^{\circ} \mathrm{B}$ (Singh \& Babita, 2002).

d) Late Bedana: the Late Bedana or Late Seedless is late ripening cultivar yielding fruit $60-80 \mathrm{~kg}$ per tree. This cultivar is sized medium but the pulp content is more. Fruits are of conical shape with vermillion to carmine colour along with dark blackish brown tubercles at maturity. The TSS content of pulp is $18-20^{\circ} \mathrm{B}$ with low acidity. Seeds are very small, chocolate coloured and fusiform shaped (Singh \& Babita, 2002).

e) Bombai: this cultivar is important in West Bengal which matures generally in the second week of May and fruityield is $80-90 \mathrm{~kg}$ per tree. Fruits are large, heart shaped and the weight ranges from $15-20$ o with TSS of $170 \mathrm{OB}$. The mature fruits are carmine red in colour with uranium green skin background. The aril is greyish white, soft, juicy, containing $11 \%$ total sugar and $0.45 \%$ acidity. The seed is elongated, smooth and shiny having light chocolate colour (Singh \& Babita, 2002).

f) Dehradun: fruits of this cultivar are medium to large in size, weighs around $15.2 \mathrm{~g}$ and has oblique heart to conical shape. The skin of the fruit looks very attractive (rose pink colour) as it ripens. The pulp is greyish white, moderately juicy having TSS of $180 \mathrm{oB}$. Total sugar and acidity contents are $10.4 \%$ and $0.44 \%$ respectively. Seeds are small, shrunken and most of them are oblong shaped. The skin of this cultivar prone to cracking when rainfed (Singh \& Babita, 2002).

g) Gulabi: this late maturing variety's quality gets affected by rain. The tree bears medium to large fruits of medium to oblong shape. The rind colour changes with maturity from shrimp red to carmine red and the fruit pulp is firm, greyish white in colour. The TSS content of the pulp is $18.2^{\circ} \mathrm{B}$ with having $10.7 \%$ total sugar and $0.49 \%$ titratable acidity. The shining chocolate coloured seed is big, heavy and oblong-cylindrical shaped (Singh \& Babita, 2002).

h) Ellaichi: this important cultivar in West Bengal is less 


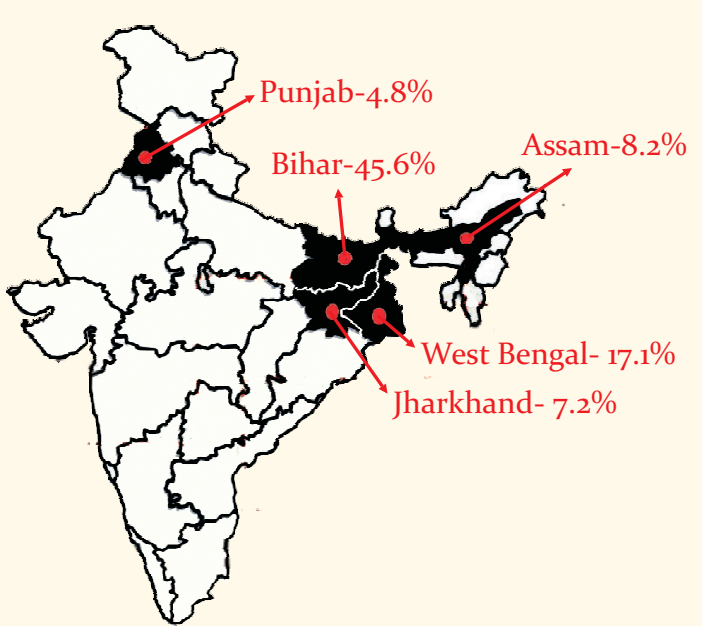

Figure 1: Leading litchi producing states in India (2010-11)

prone to sunburn and cracking. It is a mid-season cultivar yielding around $50-60 \mathrm{~kg}$ fruits annually. Fruits are conical, marigold-orange red coloured weighing around 12-15g each. The pulp is creamy white, soft and juicy with pleasant flavor. This variety has TSS content of $18^{\circ} \mathrm{B}, 11.5 \%$ total sugar and $0.45 \%$ acidity with smaller seed size (Singh \& Babita, 2002).

\section{Litchi based products:}

Any product that can be obtained from any part of litchi can be called as the litchi based product (Karizaki, 2017). The recent status of processed litchi products is dried litchi, canned litchi, litchi juice, frozen litchi, litchi wine, litchi nuts, synbiotic and probiotic litchi drinks etc.

a) Dried Litchi: Dried litchi has availability round the year and thus gained more importance commercially (Song et al., 2015). Litchis can be dried after separation of pulp by different drying methods like (i) Air drying (AD), (ii) Microwave-assisted air drying (MWAD), (iii) Microwave-assisted vacuum drying (MWVD) and (iv) Freeze drying (FD). The final moisture content of the product is generally around $7 \%$. The two microwave drying methods are better with respect to AD and it has got advantage over FD with respect to drying time. The drying time for MWVD, MWAD, AD, FD are 120 minutes, 140 minutes, 22 hours and 60 hours respectively. However, the organoleptic property is best in case of MWVD (Song et al., 2015).

b) LitchiJuice, Squash, Syrup, and Cordial: litchi juice is the most common and favorable litchi based product. It is one of the most widely available product in commercially and can be used as a natural antioxidant drink (Zheng et al., 2014). Brownish discolouration of juice is commonly observed when the juice is preserved at room temperature which can be prevented by keeping bottles of juice at a low temperature of $4-5^{\circ} \mathrm{C}$. (Singh et al., 2012).

The concentration of fruit juice results in reducing the bulk, which reduces the packaging, transportation and storage costs. It also opens the path of economic utilization of perishable fruits during its peak season. Therefore, there is a need to process litchi into value added juice concentrate to make this seasonal fruit available round the year (Vijayanand et al., 2010). Squash contains $25 \%$ juice and TSS must not be less than $40^{\circ} \mathrm{B}$. Litchi syrup is the sweetened juice of a litchi with a high concentration of sugar and low concentration of fine pulp of the fruit usually with a low acid content. Cordial is a clear, sparkling, sweetened juice from which the pulp and other suspended materials are completely removed.(Singh et al., 2012).

c) Litchi Jelly: the juice is first extracted from mature litchi fruits and the quantity of pectin is tested by alcohol test. As per pectin strength of the extracted juice, a required quantity of sugar is added and the jelly is prepared (Singh et al., 2012).

d) High pressure processed Litchi juice and beverages: fruit beverages are considered as very refreshing, appetizing and easily digestible drinks for human consumption (Jayachandran et al., 2015; Wall, 2006). It is one of the main ingredients of a healthy diet (Jayachandran et al., 2015). High levels of polyphenols and ascorbic acids are retained after high-pressure processing and therefore is of very much importantce(Chaikham et al., 2017). HPP is used as fruit preservation method even though it can't retain native fruit quality but is better than traditional thermal processes (Chaikham et al., 2017).

e) Probiotic Litchi based beverage: in recent times, there has been an increasing trend of switching simple food towards functional food and therefore litchi juice is used which has got natural antioxidants, which can further be increased by adding probiotics. Probiotics benef its the host by acting as a living microbial supplement (Zheng et al., 2014; Prakash et al., 2017). Fermentation of fruit juice by probiotic bacteria improves nutritional, sensorial and also shelf life properties of fruit juice (Zheng et al., 2014; Ankolekar et al., 2012).

f) Synbiotic Litchi based beverage: when probiotic and prebiotic reside together in a same product it is said to be synbiotic. The need of Probiotic and Synbiotic fruit and vegetable based beverage was developed due to several risk factors associated with dairy based functional beverages like high cholesterol content, allergic and intolerance factors to name a few (Zheng et al., 2014).

To enhance survival of probiotics in food matrix, microencapsulation technique can be adapted by using Whey Protein Concentrate (WPC) as wall material. Prebiotics such as inulin, gum acacia, oligo fructose can be added to the litchi drink to produce a synbiotic litchi juice (Prakash et al., 2017).

g) Canned Litchi: the canned litchi is of excellent quality and it has great demand both in India and abroad. The 
canned litchi has a shelf life of around 3 months, after that pink discolouration occurs which may be due to formation of tin-anthocyanin complex (Singh et al., 2012).

h) Frozen Litchi: freezing of whole fruits is best and most easy method to preserve the natural flavor \& quality of litchi for a long time (Singh et al., 2012). A successful FD process retains the volume of the material which is a major problem in case of dried litchi. Drying temperatures less than the temperature of glass transition during heating allow ice removal within the solid. But temperatures more than ice melting temperature could collapse the structure of the fruit (Roos, 1991).The structure of materials containing sugars may collapse during drying if the ice temperature within the material is higher than the temperature of collapse (Huang et al., 2017).

i)Litchi honey: honey is a very well-known global product popular for its organoleptic as well as nutritive properties (Islam et al., 2014). The litchi honey possesses intense balsamic (licorice and menthol) and woody aroma. It is generally thick, astringent, bitter, slightly acidic and pale yellow in colour (Mahattanatawee et al., 2014). The antioxidant property of litchi honey is moderately high as it contains high amount of polyphenols, ascorbic acid (Vitamin-C), and flavonoids. Litchi honey contains moderately low moisture $(<20 \%)$ and increase in TSS content with the decrease in $\mathrm{pH}$ indicates good quality of honey (Islam et al., 2014)

j) Litchi wine: litchi is a distinctly delicious fruit with good source of vitamins and minerals. Litchi fruits have TSS generally around $20^{\circ} \mathrm{B}$ with $27 \%$ reducing sugar and $0.5 \%$ acidity which is highly suitable for producing wine. The wine produced a clean, light amber colour, an attractive aroma of natural litchi fruit and a harmonious wine taste and typically contains 5-6\% alcohol (Singh et al., 2012).

\section{Processing technique :}

a) Dried litchi : Fresh litchi fruits with uniform size, free of microbial contamination and physical damage are preferred for drying application.For Air Drying (AD), electro-thermostatic blast oven can be used to dry peeled litchis. (Song et al., 2015). Microwave-Assisted Vacuum Dryer (MWVD) in which the materials to be dried can be rotated in the cavity developed by Cui et al. (2003). MWVD has been used to dry peeled litchis with $1.8 \mathrm{~W} / \mathrm{g}$ microwave power and applied vacuum pressure of $4 \mathrm{kPa}$ (Song et al., 2015; Mothibe et al., 2014).

The Microwave coupled Air Drying (MWAD) system consisted of microwave power sources, a cavity, a hot air source, and a control system. The temperature of the air has been controlled at $60^{\circ} \mathrm{C}$, and air velocity was maintained with an adjustable fan.After drying for $65 \mathrm{~min}$, the microwave oven was turned off with the Air Dryer on until the moisture content reduced to $10 \%$ (wb)(Songs et al., 2015; Ilknur, 2007).

For Freeze Drying (FD), freeze dryer has been used to dry peeled litchis at $-30^{\circ} \mathrm{C}$ for $12 \mathrm{~h}$, and the plate temperature being $-49^{\circ} \mathrm{C}$ and pressure at $4 \mathrm{kPa}$ (Songs et al., 2015; Cui et al., 2008).

b) Litchi juice, squash, syrup and cordial: litchi juice is generally extracted by basket press and preserved by adding $\mathrm{SO}_{2}$ or Potassium meta-bi-sulphite as preservatives. Sugar, citric acid, vanilla or rose essence addition is common to these products preparation.Juice is then filled in sterilized bottles followed by capping and storing. Litchi squash, the syrup is prepared by this technique varying the amount and time of addition of the ingredients. To prepare cordial the supernatant (clear juice) is used after filtering followed by addition of all the ingredients. Before bottling the cordial is again filtered through muslin cloth. (Singh et al., 2012).

c) Litchi jelly: the juice is first extracted and the required quantity of sugar is added and cooked. A citric acid concentration of $7 \mathrm{~g} / \mathrm{kg}$ of sugar is used and then mixed with water at the time of cooking. When the endpoint reaches at $105^{\circ}$ to $107^{\circ} \mathrm{C}$, cooking is stopped and the product is filled in glass jars. Good jelly formation requires a high ratio of juice to sugar and thus Litchi jelly made with the juice of $18 \%$ soluble solids, combined with sugar in a 55:45 ratio.The $\mathrm{pH}$ of the juice should be adjusted with phosphoric acid to 3.7 and subsequently to $\mathrm{pH} 3.2$ with citric acid. It was found that the addition of $1 \%$ commercial slow set pectin to litchi jelly is sufficient for good gel formation (Singh et al., 2012).

d) High pressure processed litchi juice \& litchi based beverages: to peeled and destoned litchi pulp, calium chloride, and citric acid are added to the concentration of $10 \mathrm{~g} / \mathrm{L}$ and $1 \mathrm{~g} / \mathrm{L}$ respectively. A certain amount of distilled water and sugar syrup is added to it and vacuum packed in small nylon/polyethylene bags for a high-pressure application. Pressure is applied at $100-600 \mathrm{MPa}$ for 20 minutes (Chaikham et al., 2017). Maximum inactivation of enzymes like PPO and POD that has been attained is $39.7 \%$ and $29.1 \%$ by applying 600 MPa pressure for 15 minutes (Kaushiket al., 2016).

e) Litchi based probiotic beverage : litchi is first peeled and destoned before processing through a pulper. Then it is passed through a filter (100 mesh). Heated litchi juice $\left(95^{\circ} \mathrm{C}\right.$ for 1 minute) is cooled down rapidly to $25^{\circ} \mathrm{C}$. This juice is either high hydrostatic pressure processed (500 MPa for 2 minutes) or thermally pasteurized $\left(95^{\circ} \mathrm{C}\right.$ for 1 minute). The litchi juice is immediately inoculated with Lactobacillus casei to initial concentration of 5 log $\mathrm{CFU} / \mathrm{ml}$ after heat or HPP treatment and then incubated at $30^{\circ} \mathrm{C}$ for 18 hours. Before inoculation, $\mathrm{pH}$ is adjusted to 5.6 with an addition of sterile $\mathrm{NaOH}$ solution. After fermentation, the juice is bottled in PET bottles (Zheng et 
al., 2014).

f) Litchi based synbiotic beverage : to activate probiotic culture of Lactobacillus casei, the prebiotic material (inulin/ oligosaccharide/gum acacia) is added at a proper concentration. The mixture is then homogenized at around $10,000 \mathrm{rpm}$ for 15 minutes. It is further incubated at $37^{\circ} \mathrm{C}$ for 2 hours. Finally, spray dried (Inlet temperature: $165^{\circ} \mathrm{C}$ \& outlet temperature: $75^{\circ} \mathrm{C}$ ) to powder form and stored at $4{ }^{\circ} \mathrm{C}$. Finally, litchi juice is mixed with probiotic power along with sugar and distilled water to form the symbiotic beverage (Prakash et al., 2017).

g) Canned litchi : fully mature ripe fruits of Shahi, Early Large Red, Early Seedless, Rose Scented Purbi or Bedana are selected for the canning process. To destoned litchi pulp, sugar syrup of $30-35^{\circ} \mathrm{B}$ is added as filling liquor. Sugar syrup may be mixed with rose or vanilla essence along with the addition of $0.2 \%$ citric acid. Exhausting completes when the can centre reaches $85^{\circ} \mathrm{C}$ and is kept for 5 minutes. After sealing the cans are processed in boiling water for 30 minutes. The cooled cans are wiped dry (Singh et al., 2012).

h) Frozen litchi : peeled litchi fruit can be frozen in syrup with or without seed.The lab-scale vacuum freeze dryer has been used with a minimum absolute pressure of freeze dryer being $1 \mathrm{~Pa}$ and the lowest temperature of cold trap kept $-55^{\circ} \mathrm{C}$. Lychees were dried by FD until the final moisture content reached around 10\% (wet basis) (Huang et al., 2017). The fruits remain excellent in condition for around 12 months when cooled rapidly and stored at $-18^{\circ} \mathrm{C}$ to $-25^{\circ} \mathrm{C}$ (Singh etal., 2012).

i) Litchi honey : litchi is a highly cross-pollinated fruit and pollination is a rule for production of litchi with good quality (Islam et al., 2014; Choudhary et al., 2015). Honey bees play a significant role in pollination process, therefore yielding high-quality fruit. Honey bees of Apis mellifera (Italian honey bees) species contribute to producing litchi honey (Choudhary et al., 2015). When worker bees are around 20 days old, they leave the hive to collect nectar (the sweet secretion produced by glands of flowers). The bee sucks out the nectar and deposits nectar in the honey sac. The bee's glandular system emits enzymes that enrich nectar. Pollen attaches to bees leg and hair during the process. When worker bee can't hold any more nectar, it returns to the hive. Then honey undergoes further ripening process and gets stored in honeycomb, poured into tanks and heated to $48.9^{\circ} \mathrm{C}$ to melt down the crystals for 24 hours. Then flash heating is applied at $73.8^{\circ} \mathrm{C}$, filtered through paper, flash cooled back to $48.9^{\circ} \mathrm{C}$ within around seven seconds. Then the honey is poured intojars (Bonney, 1990).

j) Litchi wine : litchi wine, a fermented beverage generally contains 6-11\% alcohol (Singh et al., 2012). Mature litchi fruits are washed, peeled and then dipped in sugar solution of $70^{\circ} \mathrm{B}$ for 4 hours at a temperature of $50^{\circ} \mathrm{C}$ followed by pulping by a pulper. The TSS content is adjusted to $22^{\circ} \mathrm{B}$. A 24 -hour old active culture of yeast (Saccharomyces cerevisiae) is used to carry out alcoholic fermentation. The fermentation is carried out until the TSS reached $7^{\circ} \mathrm{B}$. The wine gets aged and then blended with an equal amount of fresh litchi juice, followed by distribution into glass bottles and closing with wooden corks (Kosseva et al., 2017).

\section{Conclusion:}

Litchi is one of most relished fruits having ample amount of bioactive compounds like flavonoids, Vitamin Bcomplex, ascorbic acid in it to confer significant health benefits. The health benefits due to these active compounds include disease-fighting ability, better heart health and blood regulation and free radical scavenging capacity etc. However, a seasonal fruit like litchi has its occurrence in the market only for one to two months. Though Litchi is a very popular fruit in most of the places in India, there is much to do to commercialize litchi and litchi based products in the near future. Due to the medicinal, sensorial and nutritional aspects of litchi fruit, more new products can also be developed retaining the characteristics of the fruit which will have extended shelf life and more viable to the Indian market. More novel technologies might be applied in order to produce products with low microbial contamination, better sensorial quality with bioactive compounds being unharmed. Value-added products also could be developed by using more varieties of probiotic bacteria alone or with different prebiotic matrices in different concentrations. Further research may also be done with respect to production and export scenarios of the processed foods from litchi.

\section{References:}

Ankolekar, C., Pinto, M., Greene, D., \& Shetty, K. (2012): In vitro bioassay based screening of antihyperglycemia and antihypertensive activities of Lactobacillus acidophilus fermented pear juice. Innov. Food Sci. Emerg. Technol., 13:221230.

Beristain, C.I., Cruz, S.F., Lobato, C.C., Pedroza, I.R., Rodriguez, H.M. E. \& Verde, C.J.R. (2006): Applications of soluble dietary fibers in beverages. Rev. Mex. Ing. Quím., 5: 81-95.

Bonney, R.E. (1990): Hive Management: A Seasonal Guide for Beekeepers (Storey's Down-To-Earth Guides). Pub. by: Garden Way Publishing.

Chaikham, P., Rattanasena, P., Phunchaisri, C. \& Sudsanor, P. (2017): Quality changes of litchi (Litchi chinensisSonn.) in syrup due to thermal and high pressure processes. $L W T$ Food Sci. Technol., 75: 751-76o.

Chen, H.B. \& Huang, X.M. (2014): Overview of litchi production in the world with specific reference to China. Acta Hortic., 1029:25-33.

Choudhary, M.L., Patel, V.B., Siddiqui, M.W. \& Verma, R.B. (2015): 
Climate issues affecting sustainable litchi (Litchi chinensis Sonn.) production in Eastern India. Climate dynamics in horticultural science: Impact, Adaptation and Mitigation (Vol.-2). Pub. by::AppleAcademic Press.

Cui, Z.W., Li, C.Y., Song, C.F. \& Song, Y. (2008): Combined microwave vacuum and freeze drying of carrot and apple chips. Dry Technol., 26 (12):1517-1523.

Cui, Z.W., Xu, S.Y. \& Sun, D.W. (2003): Dehydration of garlic slices by combined microwavevacuum and air drying. Dry Technol., 21(7): 1173-1184.

Huang, F., Zhang, R., Liu, Y., Xiao, J., Su, D., Yi, Y., Wang, G., Wei, Z. \& Zhang, M. (2016): Characterization and mesenteric lymph node cells-mediated immunomodulatory activity of litchi pulp polysaccharide fractions. Carbohydr Polym.,. 152:496503.

Huang, F., Zhang, R., Yi, Y., Tang, X., Zhang, M. \& Su, D. (2014): Comparison of physicochemical properties and immunomodulatory activity of polysaccharides from fresh and dried litchi pulp. Molecules, 19(4):3909-3925.

Huang, L.L., Qiao, F., Peng, G. \& Fang, C.F. (2017): Analysis for difficulty during freeze drying Feizixiao Lychees. $[$. Food Quality., 2017: 1-8.

Hulle, N.R.S., Chakraborty, S. \& Rao, P.S. (2017): Effects of high pressure processing on the quality attributes of Aloeveralitchi mixed beverage. Innov. Food Sci. Emerg. Technol., 40: 68-77.

Ilknur, A. (2007): Microwave, air and combined microwaveairdrying parameters of pumpkin slices. LWT - Food Sci. Technol., 40(8):1445-1451.

Islam, M.S., Jothi J.S., Islam, M. \& Zubair, M.A. (2014): Antioxidant and Physico-Chemical Properties of Litchi Honey Procured from Gazipur and Tangail District, Bangladesh. L. Entomol. Zool. Stud., 2(5): 207-211.

Jayachandran, L.E., Chakraborty, S \& Rao, P.S. (2015): Effect of high pressure processing on physicochemical properties and bioactive compounds in litchi based mixed fruits beverage. Innov. Food Sci. Emerg. Technol., 28:1-9.

Karizaki, V.M. (2017): Iranian dates and ethnic date-based products. J.Ethnic Food., 4:204-209.

Kaushik, N., Kaur, B.P. \& Rao, P.S. (2016): Inactivation of polyphenol oxidase and peroxidase enzymes during pulsed, static and cyclic inactivation of litchi (Litchi chinensis) juice. Food Bioprod. Process., 100: 412-423.

Kosseva, M., Joshi, V.K. \& Panesar, P.S. (2017): Specif ic features of table wine production technology, Science and technology of Fruit Wine production, p. 295-461, Pub. by: Academic Press.

Kumar, B. (2011): Indian Horticulture Database. Pub. by: Ministry of Agriculture, Government of India. p. 278.

Mahattanatawee, K., Perez-Cacho, P.R, Soldevilla, H. G. \& Rouseff, R. L. (2014): Investigation of Four Tropical Unifloral Honey Aromas using Sensory and GC-Olfactometer Analyses. Flavour Science. p. 257-261, Pub. by: Academic
Press.

Mothibe, K.J., Wang, C.Y., Mujumdar, A.S. \& Zhang, M. (2014): Microwave assisted pulse-spouted vacuum drying of apple cubes. Dry. Technol., 32(15):1762-1768.

Prakash, K.S., Bashir, K. \& Mishra, V. (2017): Development of Synbiotic Litchi Juice Drink and its Physiochemical, Viability and Sensory Analysis. L. Food Process. Technol., 8(12): o1-o6.

Reyes, A., Castillo, J.F., Montiel, R.G.C. \& Carrillo, M.L. (2016): Phenolic content and antioxidant activity in litchi fruit (Litchi chinensis Sonn.) pericarp.Jokull J., 66(5):63-73

Roos, Y. H. (1991): Amorphous state and delayed ice formation in sucrose solutions. International Journal of Food Science \& Technology. 26(6): 553-566.

Singh, G., Nath, V., Pandey, S.D., Ray, P.K \& Singh, H.S. (2012): The Litchi, Pub. by: FAO of United Nations, New Delhi, India.

Singh, H.P. \& Babita, S. (2002): Lychee production in India. Pub. by: FAO of United Nations, New Delhi, India.

Sivakumar, D. \&Korsten, L. (2011): Litchi (Litchu chinensis Sonn.) (Chap 15). Postharvest biology and technology of tropical and subtropical fruits. (Vol. 3) Pub. by: Woodhead publishing. In ed:Yahia, E. 361-407

Song, C.F., Cui, Z., Jin, G.Y., Mujumdar, A.S. \& Yu, J.F. (2015): Effects of Four Different Drying Methods on the Quality Characteristics of Peeled Litchis (Litchi chinensis Sonn.). Dry. Technol., 33(5): 583-59o.

Vijayanand, P., Kulkarni S. G. \&Prathibha G. V. (2010): Effect of pectinase treatment and concentration of litchi juice on quality characteristics of litchi juice. J Food Sci. Technol., 47(2): 235-239.

Vural, H. \& Karaman, S. (2009): Socio-Economic Analysis of Beekeeping and the Effects of Beehive Types on Honey Production. Not. Bot. Hort. Agrobot. Cluj. 37(2): 223-227.

Wall, M.M. (2006): Ascorbic acid and mineral composition of longan (Dimocarpus longan), lychee (Litchi chinensis) and rambutan (Nephelium lappacium) cultivars grown in Hawaii. L. Food Compos. Anal., 19: 655-663.

Chen, W-H., (1949): Culture of lychee. Pub. by: Florida State Horticultural Society. p.223-226

Yang, B., Wang, H., Prasad, N.,Pan, Y. \& Jiang, Y.(2011): Use of litchi (Litchi sinensis Sonn.) seeds in health. In Preedy, V.R., Watson, R.R. \& Patel, V.B. (ed.) Nuts and seeds in health and disease prevention(chap 82), p. 699-703, Pub. by: Academic press.

Zhao, L., Hu, Z.Y., Yu, X.L. \& Wu, Z.X. (2014): Processed products from litchi and longan and their processing technology in China. Acta Hortic., 1029:379-384.

Zheng, X., Yu, Y., Xiao, G., Xu, Y., Yu, J., Tang, D. \& Zhang, Y. (2014): Comparing product stability of probiotic beverages using litchi juice treated by high hydrostatic pressure and heat as substrates. Innov. Food Sci. Emerg. Technol., 23:61-67. 